\section{NATURE OF FORCES BETWEEN LARGE MOLECULES OF BIOLOGICAL INTEREST*}

\author{
By Prof. LINUS PAULING \\ California Institute of Technology
}

A S I look at a living organism, I see reminders of many questions that need to be answered. Not all these questions are obviously important, nor would their answers be useful-but we want them answered. Thomas Wright in 1601 said, "Nothing is so curious and thirsty after knowledge of dark and obscure matters as the nature of man"- - of scientific men especially, he might have said.

What is skin, fingernail ? How do fingernails grow? How do I feel things ? How are nerves built and how do they function? How do I see things ? H.ow can I smell things, and why does benzene have one smell and iso-octane another? Why is sugar sweet and vinegar sour? How does the hæmoglobin in my blood do its job of carrying oxygen from the lungs to the tissues? How do the enzymes in my body break up the food that I eat, burn it to keep me warm and to permit me to do work, and build new tissues for me from the food fragments ? Why do I catch cold when exposed through contact with an ailing person, get pneumonia, and then recover after treatment with a specific antiserum or a sulpha drug ? How does penicillin carry out its wonderful function of fighting disease? Why am I immune to measles, whooping cough, poliomyelitis, smallpox, whereas some other people are not? And finally, why is it that my children, as they grow and develop, become human beings, and show characteristics similar to mine, and their mother's-how have these characters been transmitted to them ?

The basic answers to all these questions are not to be found in books. Even though Chaucer said

"For out of olde feldes, as men seith, Cometh al this newe corn fro yeer to yere; And out of olde bokes, in good feith, Cometh al this newe science that men lere",

he was before long corrected by Francis Bacon :

"Books must follow sciences, and not sciences books".

To understand all these great biological phenomena we need to understand atoms, and the molecules that they form by bonding together; and we must not be satisfied with an understanding of simple moleculesnitrous oxide, NNO, that Davy used to produce hysteria; benzene, $\mathrm{C}_{6} \mathrm{H}_{6}$, discovered by Faraday; penicillin, containing forty atoms in its molecule. We must also learn about the structure of the giant molecules in living organisms, such as insulin, with 2,000 atoms in its molecule, hæmoglobin, with about 10,000 , the disease-producing viruses, a thousand times larger still.

Just two thousand years ago the Roman poet Lucretius wrote

"Wine flows easily because its particles are smooth and round and roll easily over one another, whereas the sluggish olive oil hangs back because it is composed of particles more hooked and entangled one with another".

- Friday Evening Discourse at the Royal Institution, delivered on February 27.
This is essentially the modern point of view, expressed by Lucretius, of course, only as a surmise, whereas to us it is a fact, of which we have a detailed understanding. Lucretius went beyond us in inter. preting the taste also of substances in terms of the shape of their molecules, writing

"There is this, too, that the liquids of honey and milk give a pleasant sensation of the tongue, when rolled in the mouth; but on the other hand the loathsome nature of wormwood and biting centaury set the mouth awry by their noisome taste; so that you may easily know that those things which can touch the senses pleasantly are made of smooth and round bodies, but that on the other hand all things which seem to be bitter and harsh, these are held together with particles more hooked".

I shall now present a detailed discussion of the shapes of molecules, and the forces between molecules, in order to show the extent to which this surmise, too, of Lucretius is substantiated.

Even though hæmoglobin is spoken of as a large molecule, the molecule is very small in comparison with our usual scale. If I look at my hand or watch a few feet away, the atoms subtend the same angle that oranges would on the surface of the moon. The molecules might thus be described as an aggregate of oranges, held together by bonds which in actual molecules are electrons circulating between the atoms. On this scale of $250,000,000$-fold linear magnification, the nitrous oxide molecule of Davy's laughing gas consists of three atoms in line, $\mathrm{N}-\mathrm{N}-\mathrm{O}$, the distance between the two nitrogen atoms being about $1 \cdot 12$ in. and between the nitrogen and oxygen atoms $1.19 \mathrm{in}$. (in the molecules themselves $1.12 \mathrm{~A}$. and $1 \cdot 19 \mathrm{~A}$., where $1 \mathrm{~A}$. is $1 / 100,000,000 \mathrm{~cm}$.). Faraday's benzene molecule consists of twelve atoms: six carbon atoms arranged at the corners of a regular hexagon, with the carbon-carbon distance $1 \cdot 39 \mathrm{~A}$., and six hydrogen atoms, in the same plane, at the corners of a larger hexagon, the distance of each hydrogen atom to the carbon atom to which it is attached being $1.06 \mathrm{~A}$. The structure of penicillin, determined by Mrs. Hodgkin and her collaborators, is also known, as are the structures of many hundreds of simpler molecules.

As yet the detailed atomic structure of no protein molecule has been determined; but the vigour of the attack that is being made and the increasing power of the marvellous methods of investigation used in structural study permit the confident hope that the next decade or two will bring the solution of this great problem.

Much information is already available, however, about the general sizes and shapes of large molecules of biological importance, and also about their function. The most striking general property of these molecules is the specificity of their activity. For example, hæmoglobin, the red protein in the red cells of the blood, has the specific property of combining with oxygen in the lungs, and then releasing this oxygen in the tissues, thus making it available for the oxidation of foods. There is no other substance known that is able to combine with oxygen and release so large a fraction of the combined oxygen reversibly with the small change in partial pressure of oxygen existing between the lungs and the tissues. Then there are the enzymes, such as those involved in the catalysis of the processes of degradation and oxidation of foodstuffs. These substances all show a high degree of specificity in their action : in general, 
a particular enzyme serves the purpose of speeding up a particular single chemical reaction in the body. Specificity is shown in a striking way by antibodies. These are substances produced in the living body in response to its invasion by foreign organic material, such as viruses or bacteria. They have the power of combining specifically with the material (the antigen) that led to their production, and of neutralizing or incapacitating the antigen. Thus an antitoxin is able to neutralize its homologous toxin; an antibody against a virus or bacterium is able to prevent the virus or bacterium from reproducing, and thus to aid in the control of disease. An unfortunate incidental effect of this protective mechanism of the body is the occasional production of protein sensitization, leading to asthma and hay fever. Sufferers from protein sensitization, such as those people who are sensitive to egg white (ovalbumin), can testify as to the specificity of the reaction and to its delicacy.

The specificity of serological reactions can be shown by simple serological tests carried out in the laboratory. Thus if a minute amount of ovalbumin is injected into a rabbit, it is found that after a week or two the serum of the rabbit's blood will produce a precipitate when mixed with a solution of ovalbumin, whereas the serum of an uninoculated rabbit will not produce such a precipitate. The precipitate contains ovalbumin from the ovalbumin solution that is added to the serum, and antibody molecules from the serum of the rabbit. These antibody molecules are protein molecules, with molecular weight about 160,000 , corresponding to the presence in the molecule of about 20,000 atoms. These anti-ovalbumin molecules have the power of combining with molecules of ovalbumin, but in general not with molecules of other substances. Only if another substance is extremely closely similar in its structure to the ovalbumin with which the rabbit was originally injected can the antibody combine with it. Thus a precipitate, somewhat smaller in amount than with hen ovalbumin, is formed by antibodies produced by hen ovalbumin when mixed with a solution of duck ovalbumin ; but no precipitate is formed when these antibodies are mixed with a solution of ovalbumin from the eggs of birds of other species.

Dr. Karl Landsteiner showed by his experiments that animals are able to manufacture antibodies specific to chemical groups that do not exist in Nature. The power of formation of antibodies able to combine only with an injected antigen is hence not a power that was developed in the course of evolution, in response to interaction with this antigen at some earlier age, and in a particular individual called into operation by the inoculating injection; but is instead a general power, which enables the animal to cope with a foreign material, even of completely foreign nature to the animal and its ancestors throughout its course of evolution.

I became interested in the problem of the structure of antibodies in 1936, as the result of conversations with Dr. Landsteiner. I found that the complex phenomena of immunology could be clarified and brought into order by a theory of the structure of antibodies based upon the idea of the folding of the basic polypeptide chain of the protein precursor of the antibody into the most stable of the configurations accessible to it. This theory of the structure and process of formation of antibodies involves the acceptance of the suggestion that antibody and antigen have molecular structures that are mutually complementary, originally made by Breinl and
Haurowitz, Jerome Alexander, and Stuart Mudd. If the molecule of gamma globulin that might become an antibody is considered to consist of a chain that might fold up into any one of a large number of configurations, with essentially the same stability, then in the presence of a molecule of antigen that configuration would be selected which is stabilized by interaction with the antigen. The configuration that would be stabilized is the one in which there is the greatest force of attraction between the folded polypeptide chain and the molecule of antigen; and this greatest force of attraction would result from the assumption by the folding polypeptide chain of a configuration which permits the parts of the chain to approach as closely as possible to a portion of the surface of the antigen molecule, and which also brings positive charges in the chain in close proximity to negative charges in the antigen, and brings hydrogenbond-forming groups in the chain into juxtaposition with their complementary hydrogen-bond-forming groups in the antigen. A very high degree of specificity can be obtained if the surface area over which the complementariness of structure is exercised is great enough to include a good number of interacting structural units.

Experiments carried out with antibodies and antigens have shown that the configuration of the antibody molecules is very closely complementary to that of the surface of the homologous antigen ; the antibody reflects or reproduces, in a negative way, the shape of the surface of the immunizing antigen to within about $1 \mathrm{~A}$. , that is, to within about one-half or one-quarter of the diameter of an atom. The forces that lead to the production of the specific bonds between antibody and antigen are thus interatomic forces that operate between atoms essentially in contact with one another, and are not long-range specific forces of attraction operating through great distances (on the atomic scale) through space.

There is a highly specific phenomenon of the chemistry of simpler substances that is closely analogous in its nature and its cause to the highly specific phenomenon of serological interaction; namely, the phenomenon of crystallization. Chemists are accustomed to using the process of crystallization as a method of purification: a crystal growing in a complex mixture of molecules is able to select from the mixture just the molecules of one kind, rejecting all others. Thus pure crystals of sugar may deposit from a jam in which there are molecules of thousands of different substances. The specificity of crystallization is the result of the same striving toward comple. mentariness and the operation of the same interatomic and intermolecular forces that are responsible for the specificity of antibodies. A molecular crystal has the structure that gives it the greatest stability, which would result from the maximum amount of attraction for each molecule in the crystal and the surrounding molecules. Each molecule in the crystal is then in a cavity that conforms in shape to the shape of the molecule itself. The molecule may be described as complementary in structure to the remainder of the crystal ; and other molecules, with different shape and structure, would not fit into this cavity nearly so well, and in general would not be incorporated in the growing crystal. We may hence say that life has borrowed from inanimate processes the same basic mechanism used in producing those striking structures that are crystals, with their beautiful plane faces, their unfailingly constant interfacial angles, and their wonderfully complex geometrical forms. 


\section{No. 4097 May 8, 1948}

I believe that the same mechanism, dependent on a detailed complementariness in molecular structure, is responsible for all biological specificity. I think that enzymes are molecules that are complementary in structure to the activated complexes of the reactions that they catalyse, that is, to the molecular configuration that is intermediate between the reacting substances and the products of reaction for these catalysed processes. The attraction of the enzyme molecule for the activated complex would thus lead to a decrease in its energy, and hence to a decrease in the energy of activation of the reaction, and to an increase in the rate of the reaction. Although convincing evidence is not yet at hand, I believe that it will be found that the highly specific powers of self-duplication shown by genes and viruses are due to the same intermolecular forces, dependent upon atomic contact, and the same processes of replica formation through complementariness in structure as are operative in the formation of antibodies under the influence of an antigen. I believe that it is molecular size and shape, on the atomic scale, that are of primary importance in these phenomena, rather than the ordinary chemical properties of the substances, involving their power of entering into reactions in which ordinary chemical bonds are broken and formed.

Even though the general picture of some important biological processes is becoming clear, our present knowledge of the detailed structure of the complex substances of biological importance is vague. We may expect that as more precise information about the structure of these molecules is obtained in the future, a more penetrating understanding of biological reactions will develop, and that this understanding will lead to great progress in the fields of biology and medicine.

\section{SYNOPTIC WEATHER MAPS FOR THE ANTARCTIC}

$\mathrm{T}$ HE publication in 1946 of volume 6 of the Scientific Reports, Series B, dealing with the meteorology of the Australasian Antarctic Expedition 1911-14, and, more recently, of vol. 7 of the same series (Sydney : Gov. Printer, 1947. 40s.), is understood to complete the scientific literature dealing with this Expedition. Sir Douglas Mawson, its leader, was fortunate enough to secure the services of the late Dr. Edward Kidson, formerly director of the New Zealand Meteorological Office, for the writing of these two reports. Unfortunately, Dr. Kidson died suddenly before his work was quite completed, and for this reason chapter 1 of vol. 6 , which was to have been an introductory chapter of a general nature, is missing, together with a final section that was to have dealt with the meteorological records of sledging parties. Vol. 7 was, however, fortunately complete.

Volume 6 is entitled "Discussions of Observations at Adélie Land, Queen Mary Land and Macquarie Island". The base in Adélie Land was in Commonwealth Bay, in about lat. $67^{\circ} \mathrm{S}$, long. $143^{\circ} \mathrm{E}$. At this base two factors combined to make temperature rather high for a land station in these latitudes, and to make the variations comparatively moderate. These factors were the presence throughout the year of open sea for more than fifty miles to eastward and more than a hundred miles to westward, and the considerable downward slope of the interior to the coast, which last prevented any stagnation of cold surface air such as was observed often enough at McMurdo Sound and to an even greater degree at Amundsen's headquarters at Framheim, still farther to the east. Much has been written about the violence and frequency here of katabatic gales from a direction slightly east of south, which represent the gravitational flow of the cold air from the high interior of Antarctica, and gave a mean annual speed of 43 miles per hour, and a monthly average of about 55 miles per hour in May 1912 and July 1913. Dr. Kidson discusses these winds in Chapter 4 of this report.

The base in Queen Mary Land was on a floating tongue of ice with a level top, and was about 14 miles from the shore of the Antarctic continent, in about lat. $66^{\circ} \mathrm{S}$., long. $95^{\circ} \mathrm{E}$. In place of the open sea off the base at Commonwealth Bay, there was the extensive pack-ice belt; although there was a steep slope from the interior to the coast, the absence of open water prevented there being the very great thermal contrast across the coast inevitable at Commonwealth Bay, and the extreme violence of the wind was absent ; while there was nothing to prevent the formation in quiet winter weather of a shallow layer of very cold air. As a result of this difference, the average diurnal variation of temperature at the Queen Mary Land base was nearly double that at Commonwealth Bay, and much lower extremes were recorded.

The weather at Macquarie Island, which is 22 miles long but only $3 \frac{1}{2}$ miles wide at the widest point, was dominated by the influence of the Southern Ocean. The latitude being about $55^{\circ} \mathrm{S}$., the island lies well within the belt of stormy westerly winds that encircle the globe between about latitudes $40^{\circ} \mathrm{S}$. and $60^{\circ} \mathrm{S}$. ; and since the station was on an isthmus only about 200 yards wide, and the island was tree. less, it was much exposed to these winds. A large part of the space devoted to the observations is taken up with an analysis of these winds, which, at least partly as a result of the local topography, were much more often from north-west than from south. west. Directions from between south-south-east and north-north-east had a total frequency of only 8 per cent.

The seventh and last of the Scientific Reports, Series B, is entitled "Daily Weather Charts extending from Australia and New Zealand to the Antarctic Continent". These cover the period February 2, 1912, to January 31,1913 , and occupy most of the volume ; but several subjects of great interest and importance are also discussed in the 31 pages of introductory and explanatory matter which precede them. Among them is that of the ring of anticyclones which encircle the southerm hemisphere in about latitude $35^{\circ} \mathrm{S}$. As Dr. Kidson points out, the regular procession of these from west to east has attracted attention ever since daily weather charts were first drawn for the Australian region. They are shown to be closely connected with the depressions and fronts of high southern latitudes, and have to be taken into account when daily charts are drawn to include the Antarctic continent. After giving a statistical analysis of the movements of these anticyclones between long. $120^{\circ} \mathrm{E}$. and $170^{\circ} \mathrm{E}$., and a discussion of the difficulties that arise in this connexion from the apparent temporary disappearance of a particular anticyclone, or from its division into two, or junction with another anticyclone, the view is put forward that the moving anticyclones originate as some periodic function either of the upper atmosphere or of 